\title{
A proposed interdisciplinary framework for the environmental management of water and air-borne emissions in maritime logistics
}

David B. Grant ${ }^{1,2^{*}}$ and Michael Elliott ${ }^{3}$

1 Hull University Business School, University of Hull, Hull, HU6 7RX, United Kingdom

2 Hanken School of Economics, Helsinki, 00100, Finland

3 Institute of Estuarine and Coastal Studies, University of Hull, Hull HU6 7RX, United Kingdom

*corresponding author d.grant@ @ull.ac.uk; telephone +44 (0)1482 347549

\begin{abstract}
This paper develops and tests a conceptual environmental risk assessment and management framework to guide businesses and other stakeholders, including government, in defining and addressing potential environmental problems in ocean shipping and port operations. The framework aims to protect the natural environment and its ecosystem services while at the same time allowing society to obtain goods and benefits from the seas. As such it integrates three elements: firstly, the criteria required to achieve sustainable management that, secondly, underpin a problem structuring method which, thirdly, can be assessed using an ISO Bow-tie industry standard analysis tool. Ocean pollution from water and air-borne discharges are used to illustrate this framework; this uses an input from an exploratory research study with maritime practitioners which investigated the framework veracity and potential for use, highlighting its potential and shortcomings.
\end{abstract}

Keywords: Ocean Pollution, Maritime Logistics and Transport, Ballast Water, 10-tenets criteria, DAPSI(W)R(M) Problem Structuring, Bow-tie analysis 


\section{Introduction}

All industry and other users of the natural environment have to demonstrate that their activities are environmentally sustainable and that they fulfil all relevant national and international legislation protecting the environment (Boyes and Elliott, 2014). It is axiomatic under the precautionary principle that an industry has to prove that it is not harming the environment whereas an environmental regulatory body does not have to prove that an industry is harming the environment. In defining and tackling environmental problems and potential problems, industry has to undertake a proper risk assessment and risk management approach that may go beyond normal environmental impact assessment requirements (Lonsdale et al., 2017). This requires a robust and legally defensible approach irrespective of whether the activity is building a new power plant or operating a vessel in coastal and international waters. Once an activity has been determined as actually or potentially causing an adverse environmental effect then there is the need to implement a management approach involving problem-alleviation measures. This requires a sound conceptual framework based on good science and fit-for-purpose approaches.

Against an increasing background and knowledge of marine effects and management, we introduce a conceptual framework to provide guidance for businesses and their stakeholders, including government, to address these issues. We use ballast water and aerial discharge pollution and other environmental effects in the logistics of ocean lane shipping and transport to illustrate the use of this framework.

We first illustrate the marine environmental effects stemming from ocean lane shipping and transport and ships resident in port developments, focusing on the Baltic Sea as a busy trading and shipping context. Building on previous work, we then define, describe and discuss three inter-linked elements underlying the framework: the 10-tenets of sustainable management and stakeholder consultation criteria (Elliott, 2013; Barnard and Elliott, 2015), the DAPSI(W)R(M) (Drivers-Activities-Pressures-State changes-Impacts (on human Welfare)-Responses (as Measures)) problem structuring method (Elliott et al., 2017), and the Bow-Tie risk assessment and management analysis approach that integrates the other two elements (Cormier et al., 2013). We then discuss our integrated, conceptual framework with implementation observations for ballast water and aerial emissions that incorporate 
our exploratory research study with maritime practitioners, e.g. shippers and port operators, to solicit their views on its veracity and potential usability. Finally, given that the application of the framework may be included in the rapidly developing field of Translational Ecology which aims to determine the science repercussions for policy and vice-versa (Enquist et al., 2017), we suggest future research and application.

\section{Theoretical and conceptual background}

\subsection{Effects of increased logistics on the marine environment - the size of the problem}

There are many marine activities potentially causing environmental problems; Halpern et al (2008) illustrated the degree of activities on the oceans and many studies have identified the large number of sea-area users (e.g. Boyes et al., 2007; Smith et al., 2016). Of these, shipping and its associated activities are a major concern. Tournadre (2014) analysed global ship density using altimeter data and found a large-scale quadrupling of traffic between the early 1990s and 2014. The only region where there was a decline of traffic is near Somalia and is related to piracy starting in 2006-2007. The distribution of growth over different ocean basins reflects the redistribution of the international trade with the largest growth in the Indian Ocean and the Western Pacific Seas.

Ocean transport combined with short-sea shipping is necessary for the intercontinental shipment of bulk cargo, bulky goods, containers and dangerous materials such as oil and gas over large distances. Its strengths include being very economic and environmentallyfriendly as regards $\mathrm{CO}_{2}$ emissions per tonne of cargo despite bunker fuel being a particularly 'dirty' fuel, handling very large transport volumes, and operating independent of weather conditions (Grant, 2012). As a result of globalization, container trade has increased on average 5\% per year over the last two decades and is currently around 350 million twenty-foot equivalent (TEU) container movements a year. Container traffic is around 42 million TEU between Asia and Europe and 31 million TEU between Asia and North America. It is of note that the 45 million TEU in Intra-Asia reflects trade between Asian countries related to sub-contracting manufacturing and providing logistics services such as consolidation for other marketplaces (Grant, 2012).

By comparison, the cruise line sector is smaller than the cargo sector although an estimated 
23 million passengers cruised globally in 2015. At an average of 3,000 passengers per cruise ship that means there are about 7,700 annual cruise ship movements. Annual growth in the sector over the last thirty years has been just over 7.2\%. As a result, many new, large cruise ships have entered the market and it was forecast that 33 new cruise ships with over 100,000 berths and an investment of US\$25 billion are planned for delivery during the period 2015-2020 (F-CCA, 2016).

Finally, there are many scheduled short- and long-haul ferry services worldwide. Holthof (2014) estimated the number of ferries globally as 1,085 large displacement ferries plus 111 freight-only, roll-on-roll-off (Ro-Ro) with a capacity exceeding 12 passengers, 222 pure freight Ro-Ro ferries with a capacity of up to 12 passengers, 1,877 lightweight fast craft 180 with car capacity and 1,697 passenger-only fast craft. He further estimated that the global ferry market carried 2.2 billion passengers, 258 million cars and 39 million Ro-Ro trailers in 2013. Ferry traffic volumes in the Baltic region in 2013 were 238 million passengers, 92 million cars and 12 million Ro-Ro trailers. Needless to say, there are various environmental effects that this increased movement of ships has on marine areas, i.e. ocean or short-sea shipping lanes and port developments.

\subsection{Environmental effects of increased logistics - water and air-borne issues}

The generally accepted major pollutants and other environmental effects from ocean and short-sea shipping include $\mathrm{CO}_{2}$ and sulphur dioxide $\left(\mathrm{SO}_{2}\right)$ emissions in ports and at sea, fuel consumption of a non-renewable resources, pollutants from ballast water, sewage and garbage discharges, space occupation that may inhibit natural ecosystem development, acidification of ocean and sea $\mathrm{pH}$ levels from $\mathrm{CO}_{2}$ and $\mathrm{SO}_{2}$ emissions (OSPAR Commission, 2009). We discuss these effects in more detail with reference to the specific examples of aerial discharges and ballast water discharge (BWD) in a conceptual model (a 'horrendogram' in Figure 2). This model has been developed from a wide knowledge of the port and navigation activities and their repercussions (e.g. McLusky and Elliott, 2004). The main consequences from navigation emanate from two sources - the ocean traffic and the port development. The former intermittently occupies sea space and discharges various materials, all of which can lead to changes to the ecosystem. The port activities again have 
these impacts but continuously occupy more space, remove or change habitats, and create obstructions. These activities can introduce and provide settlement surfaces for nonindigenous species.

Arguably the largest environmental consequences of shipping are from aerial $\mathrm{CO}_{2}$ emissions. Rigot-Muller et al. (2013) found that the maritime leg represents the major contributor to $\mathrm{CO}_{2}$ emissions in an end-to-end global supply chain that includes distant overseas destinations. Their analysis showed that such $\mathrm{CO}_{2}$ emissions could be reduced by $16-21 \%$ through direct delivery to a UK port as opposed to transshipment via a continental European port, i.e. cargo feeder systems that suggest more efficient operations. Further, McKinnon (2014) argued that by packing more products into containers, shippers could reduce the number of container movements and related $\mathrm{CO}_{2}$ emissions. The pressure to minimise shipping costs would also give these companies a strong incentive to maximise fill. He surveyed 34 large UK shippers and found that inbound flows into the UK were of predominantly low density products bound for retail stores that 'cubed-out' before they 'weighed-out;' in that they reached the volume limit of the container before reaching the weight limit. For illustration, $46 \%$ of respondents importing containerised freight claimed that $90-100 \%$ of containers received were 'cubed-out'. McKinnon (2014) also found that only approximately $40 \%$ of shippers have so far measured the 'carbon footprint' of their deep-sea container supply chains with just 6\% implementing carbon-reducing initiatives. The companies surveyed also assigned a relatively low weighting to environmental criteria in ocean carrier selection. Therefore, while many shippers have the means to influence the carbon footprint of their maritime supply chains, the survey suggested that they are not currently using them explicitly to cut $\mathrm{CO}_{2}$ emissions.

There are many operational modifications that UK shippers and their ocean carriers are implementing to improve economic efficiency, most notably slow-steaming, to help to achieve carbon mitigation efforts. Slow-steaming involves reducing the speed of a ship while at sea to reduce engine load and emissions. Slow-steaming was mooted by the Maersk Line as a response to the 2008 economic recession as the spot-market price Maersk Line received in late 2008 for shipping containers from Asia to Europe or North America was approximately US $\$ 500$ below their operating costs. The relationship between ship speed and fuel consumption is non-linear and Maersk Line calculated that by redesigning 
their shipping schedules, using nine ships instead of eight to ensure customer volumes were handled and slowing the vessel sailing speeds from 22 knots to 20 knots, they could reduce annual fuel consumption from 9,500 to 8,000 and thus also reduce carbon emissions $17 \%$ from 30,000 to 25,000 t metric tonnes of $\mathrm{CO}_{2}$ (Grant et al, 2015).

As with most countries, only a few UK ports measure and report their carbon emissions. Gibbs et al. (2014) estimated that emissions generated by ships during their voyages between ports are much larger than those generated by port activities. However, 70\% of shipping emissions occur within $400 \mathrm{~km}$ of land; thus ships contribute significant pollution in coastal regions thus affecting communities. Shipping-related particulate matter (PM) emissions have been estimated to cause 60,000 cardiopulmonary and lung cancer deaths annually with most deaths occurring near coastlines in Europe, East Asia and South Asia (Corbett et al., 2007; Winebrake et al., 2009).

It is now well-accepted that increasing atmospheric $\mathrm{CO}_{2}$ results in a slow acidification of the surface ocean (Pörtner and Karl 2014). Anthropogenic emissions of sulphur and nitrogen oxides $\left(\mathrm{SO}_{\mathrm{x}}, \mathrm{NO}_{\mathrm{x}}\right)$ create acidification and can also contribute to eutrophication of coastal, land and freshwater ecosystems (De Jonge and Elliott, 2002). There are atmospheric aerosol effects on regional and global climate, but deposition also occurs over ocean surfaces in the form of sulphuric and nitric acids. Since the late 1990s international shipping has been recognized as a significant contributor of $\mathrm{SO}_{\mathrm{x}}$ and $\mathrm{NO}_{\mathrm{x}}$ to the atmosphere on local, regional, and global scales. However, the problem is less significant in the Baltic Sea compared to the Pacific Ocean and elsewhere in Asia (Hassellöv et al., 2013).

Furthermore, sulphur emission as part of overall shipping-related particulate matter emissions is a problem for ships in port. Approximately 18 shipping lines signed the Fair Winds Charter in 2010, which is an industry-led, voluntary, unsubsidised fuel switching programme for ocean-going vessels calling at Hong Kong. The shipping lines are using fuel of $0.5 \%$ sulphur content or less although if they all switched to the cleanest type of fuel available with $0.1 \%$ sulphur, $\mathrm{SO}_{2}$ emissions would decrease by $80 \%$. In return, ship operators get a $50 \%$ reduction on port and navigation charges if registered vessels switch to burning low-sulphur diesel while berthed or anchored in Hong Kong. However, low sulphur diesel is about $40 \%$ more expensive than more heavily polluting marine 'bunker' 
diesel and the scheme only covers between 30 and $45 \%$ of this higher cost. Thus, while shipping companies including Maersk Line, Orient Overseas Container Line (OCCL), Mitsui OSK Lines and Hyundai Merchant Marine have registered fleets of 10-90 ships, other cost-conscious carriers have been more reticent. APL and Hanjin Shipping were among the companies that signed the Fair Winds Charter, but neither has registered any ships with the incentive scheme (Grant et al, 2015).

Such chemical discharges to the environment are defined as contamination unless they cause a biologically harmful effect, in which case they are defined as pollution (Gray and Elliott, 2009). More recently, the introduction of organisms, for example from the discharge of ballast water or migration on ship hulls, has also been regarded as both contamination and pollution (Elliott, 2003; Olenin et al., 2016). Hence, almost two decades of intensified research, regulatory and political activities have focussed on the prevention of harmful organisms and pathogen transfers around the world (Olenin et al., 2011).

In 2004 the International Convention on the Management of Ships' Ballast Water and Sediments was adopted to provide a common and globally uniform approach to ballast water management (BWM); it entered into force in September 2017. However, regionally different BWM approaches have developed. Ballast water exchange en route (BWE) is seen as a BWM tool and an interim solution as scientific studies have proven its limited effectiveness. In addition, the water depth and distance from shore requirements as set forth in the BWM Convention cannot be met in many circumstances (David and Gollasch, 2008). One possible solution is to adopt a Creation of Shared Value (CSV) concept whereby all stakeholders adopt the sustainability goals for issues such as BWM (Aravossis and Pavlopoulou, 2013).

Since the 1970s, the EU has developed many Directives for controlling the harmful effects of marine activities (Boyes and Elliott 2014). These are implemented by Member States and enforced through local and national enabling legislation and by national and international agencies (Boyes and Elliott 2015). For example, while a Member State has to comply with pollution control required by the EU Directives, otherwise it gets reported to the European Court of Justice which can result in infraction proceedings and fines against the state, controlling discharges within its environment is implemented under national 
legislation such as pollution control regulations which can lead to companies being fined. Hence there is the onus on businesses to be aware of the legislation and comply with it.

There are also other environmental initiatives available for ports from member trade associations. Our paper focusses on developing a risk assessment and management framework to identify, ascertain and mitigate environmental risks in operations across a wide spectrum of industrial sectors. Hence, a detailed discussion of initiatives for ports is beyond the scope here. However, Kuznetsov et al. (2015) provide a good description of the major associations and tools available to this sector, and we briefly present a few of the more widely-accepted ones as examples. One is EcoPorts (2017), which is member-based and initiated by a number of proactive ports in 1997. It has been fully integrated into the European Sea Ports Organisation (ESPO) since 2011 and its founding principle is to create a level playing field on environmental regulations and implementation through cooperation and sharing of knowledge between ports. EcoPorts provides two well-established tools to its members, a self-diagnosis method (SDM) and a port environmental review system (PERS). Another is the European Community Shipowners' Association (ECSA, 2017) founded in 1965 and a trade association representing the national shipowner associations of the EU and Norway. European shipowners control $40 \%$ of the global commercial fleet, contribute 140 billion $€$ to the EU GDP and provide employment for 2.1 million people. ECSA promotes the interests of European shipping and one of its priorities is safety and environment, working in conjunction with the International Maritime Organization (IMO). The efficacy of these initiative schemes is not considered further here as the detailed information is restricted to members.

As an example of a coherent approach, Scharin et al (2016) demonstrate that the multi-use Baltic Sea has cumulative effects from many drivers, activities and pressures which require to be addressed through a complex assessment and management system. The mostly enclosed nature of the Baltic Sea (i.e. with a poor natural water exchange) confers a lower ability to purify than more open systems and hence there are increased environmental challenges, covering larger areas and lasting longer. Lehmann et al. (2014) identified source areas in the Baltic that enable transport of potential pollution to vulnerable regions. They found that there is a higher risk of ship accidents along the shipping routes and approaches to harbours, and the spread of harmful substances is primarily controlled by 
prevailing atmospheric conditions and wind-induced local sea surface currents. Using sophisticated high-resolution numerical models, they simulated the complex current system of the Baltic and subsequent 'drift modelling' identified areas of reduced risk or high-risk areas for environmental pollution. Lehmann et al. (2014) considered that the receiving areas of fish spawning and nursery areas and tourist areas are highly-vulnerable.

Given the above comments, corporate strategic decision-making for shippers and ocean shipping lines creates challenges when it comes to sustainability in a time of economic challenges, low profit margins, rising fuel and other operating costs and global economic uncertainty. However, because of such environmental controls and despite these economic imperatives, sustainability risk strategies are required and are increasingly being imposed on the shipping industry (Kun et al., 2015). However, it is axiomatic that reducing polluting discharges and their environmental footprint is good for industry and leads to a more sustainable approach such as Elkington's (1994) 'triple bottom line' of planet (natural environment), people (society) and profits (economics) (Grant et al., 2015).

\section{Development of a Conceptual Environmental Risk Assessment and Management Framework}

Given these constraints and an increasing concern for these issues (Borja et al., 2017), a company or organization requires a robust and defendable framework or technique to incorporate sustainability into its corporate strategy including the need to assess, for example, the economic viability, technological feasibility and environmentally sustainability of that strategy (Cormier et al, 2013). Some tools and techniques currently exist although they are focussed on discrete situations and events or are not holistically inclusive. For example, Lam and Lai (2015) used an approach that integrates Analytical Network Process (ANP) and Quality Function Deployment (QFD) to illustrate how shipping companies can undertake a customer cooperation programme and achieve sustainability in their operations through $\mathrm{CO}_{2}$ emission reductions. Despite these frameworks, they do not appear to cover all the necessary aspects; hence the need for the approach described here which integrates the following three stages. 


\subsection{The 10-tenets criteria of environmental management}

Integrated environmental management requires combining many aspects into a holistic system (Elliott, 2014). The problems caused by materials (e.g. pollution) or infrastructure added to the system or removed from the system (e.g. aggregates, wetland space) require a risk assessment framework. This is then managed using the actions through vertical integration of governance and the horizontal integration of stakeholder action (Newton and Elliott, 2016). Those actions are required to ensure the structure and functioning of the natural system is protected and maintained while at the same time the goods and benefits required by society are delivered. Such a combined framework and set of tools is then termed the Ecosystem Approach (Elliott 2014).

Consideration of these interactive environmental relationships gives rise to assessing whether the strategy or strategic option fulfils various criteria related to environmental management. Elliott (2013) and Barnard and Elliott (2015) respectively proposed and developed the '10-tenets' of sustainable environmental management which require to be fulfilled to ensure that the management of, and solutions for, an environmental problem will be sustainable, successful and acceptable to society (Table 1). As such, they should fall within what is realistically possible by encompassing the socio-economic and governance aspects. Fulfilling the 10-tenets would also mean that environmental management would potentially be seen by wider society as achieving sustainability and in turn would be more likely to be accepted, encouraged and successful. The 10-tenets are self-explanatory although Barnard and Elliott (2015) interrogate and quantify these further for port and marina operations. We now turn to setting and structuring of environmental problems using a revision of the DPSIR approach: the DAPSI $(\mathrm{W}) \mathrm{R}(\mathrm{M})$ method (pronounced dap-seeworm). 
Table 1 The Ten-Tenets of Environmental Management (Source: adapted from Elliott, 2013 and Barnard and Elliott 2015)

Socially desirable/tolerable: Environmental management measures are required or at least are understood and tolerated by society as being required; that society regards the protection as necessary.

Ecologically sustainable: Measures will ensure that the ecosystem features and functioning and the fundamental and final ecosystem services are safeguarded.

Economically viable: A cost-benefit assessment of the environmental management indicates (economic/financial) viability and sustainability.

Technologically feasible: The methods, techniques and equipment for ecosystem and society/infrastructure protection are available.

Legally permissible: There are regional, national or international agreements and/or statutes which will enable and/or force the management measures to be performed.

Administratively achievable: The statutory bodies such as governmental departments, environmental protection and conservation bodies are in place and functioning to enable successful and sustainable management.

Politically expedient: The management approaches and philosophies are consistent with the prevailing political climate and have the support of political leaders.

Ethically defensible: How costs of acting are determined and calculated for current and future generations.

Culturally inclusive: Notwithstanding actions are desired and tolerated by society there may be some cultural considerations taking precedence.

Effectively communicable: Communication is required among all the stakeholders to achieve the vertical and horizontal integration encompassed in the foregoing nine tenets.

\subsection{DAPSI $(W) R(M)$ problem structuring method}

Borja and Dauer (2008), while noting that many methodologies with hundreds of indices, metrics and evaluation tools are currently available, argued that many countries have adopted the DPSIR (Drivers-Pressure-State-Impact-Response) framework to deal with the complexities of socio-environmental issues. This framework evolved over two decades (Atkins et al., 2011; Patricio et al., 2016) to originally be an environmental management paradigm as a feedback loop system in which driving forces (D) of social and economic development exert pressures $(\mathrm{P})$ on the natural environment thereby changing its state $(\mathrm{S})$, potentially resulting in impacts (I) on human health and/or ecosystem function that may elicit an environmental management response (R). Economic development, such as a port 
expansion, will invariably increase environmental pressures, some of which will be ameliorated, mitigated or compensated for through specific management actions.

As an example, increasing a port area will cause the loss of estuarine habitats such as mudflats or saltmarshes or disturb overwintering wading birds, or it may produce physical barriers to diadromous fishes such as eels and salmon migrating between the sea and the catchment (McLusky and Elliott, 2004). Such relationships between society and in this case the impact logistics and supply chain management (SCM) on the environment, and responses to such impacts can be formalised through the development of the DPSIR systems-based approach (Atkins et al., 2011).

Despite the above, there were some anomalies in the DPSIR approach that have been rectified in a new, enhanced DAPSI(W)R(M) approach (Patricio et al., 2016; Elliott et al., 2017), and which we adopt here for this paper. The Drivers are now considered to be basic societal needs (D) instead of vague indications of sectoral demands and in turn they are achieved from Activities by society (A) that in turn generate the Pressures resulting from these activities $(\mathrm{P})$. The Pressures are mechanisms that effect a State change on the natural system (S) that in turn generates Impacts (on human Welfare) (I(W)) such as changes affecting wealth creation and quality of life. These revised Impacts on human Welfare lead to Responses that can be addressed using Measures $(\mathrm{R}(\mathrm{M})$ ), a term commonly used in European Directives to indicate how management will be effected.

The ten-tenets are thus a means of achieving actions or management measures that are important for all stakeholders and are available from and carried out by the relevant stakeholders. Within the DAPSI(W)R(M) approach, State changes and Impacts (on human Welfare) together represent the changes to the receiving environment, and direct human interaction with the environment is represented not just by Responses (using Measures), but also by the Drivers as the demands on the system leading to the Activities causing the Pressures.

The 10-tenets for sustainable management predominantly apply to society and the economy rather than the natural environment; hence Barnard and Elliott (2015) emphasise that nine out of the ten have a societal, governance and economic basis. Therefore assessing environmental change is not restricted solely to natural environmental aspects of the 
Pressures (i.e. the management measures introduced in response to the State changes) but also to the human and societal consequences (i.e. the Impacts (on human Welfare)). Indeed, in the case of port operations, the ecological aspects may be the lesser of the considerations given that ports have already greatly modified the previous natural environment and that a new equilibrium state has been formed or is maintained by this physiographic change. In essence, environmental management requires us to assess the Pressures, State changes and Impact (on human Welfare) but we manage the Drivers and Activities. Indeed, 'environmental management' can be regarded as a misnomer in that usually we are not managing the environment but rather the people and their actions. For example, we assess the change to the seabed during port dredging but we manage the dredging frequency, intensity, extent and duration.

\subsection{Bow-Tie analysis}

To integrate and assess the DAPSI(W)R(M) approach and the ten-tenets criteria we can adopt what is known as the Bow-tie risk management analysis as shown conceptually in Figure 2. Fault tree analysis or FTA (Vesely et al., 1981)) and event tree analysis or ETA (Ferdous et al., 2009) have been used for risk assessment for many decades. However, these techniques share a common objective, which is to provide an assurance that a process or a system is designed and operated under an 'accepted risk' or a 'threshold' criterion together. Both FTA and ETA can be used together in the Bow-tie analysis (Ferdous et al., 2012; Cormier et al, 2013). FTA provides a graphical relationship between the undesired event and basic causes of such an occurrence while ETA is a graphical model of consequences that considers the unwanted event as an initiating event and it constructs a binary tree for probable consequences with nodes representing a set of success or failure states. The consequences of the initiating event in ETA are usually termed as events or safety barriers, and the events generated in the end states are known as outcome events.

Both techniques use the probability of basic and other events (e.g. failure or success) as quantitative inputs and determine the probability of occurrence for the top-event as well as outcome events for likelihood assessments. The ISO industry standard (IEC/ISO 2009) Bow-tie analysis has been long used in industries especially those constructing and 
operating new plant such as power plants (Cormier et al., 2013). It is a combined concept that integrates both techniques in a common platform, considering the top-event and initiating event as linked to a common event called a critical event. As with FTA and ETA, Bow-tie analysis also uses the probability of failure of basic events as input events on the FTA site and the probability of occurrence (either failure or success) of events as input events on the ETA site for evaluating the likelihood of critical and outcome events. For quantitative Bow-tie analysis, the probabilities of input events are required to be known either as precise data or defined probability density functions (PDFs) if uncertainty needs to be considered. If such quantitative information is not known then an expert judgement approach can be taken although of course this will result in only a semi-qualitative set of outcomes.

As with any risk assessment and risk management approach, the Bow-tie analysis method is initially a qualitative model for displaying links between causes, hazards and consequences and incorporating prevention and mitigation measures, but can be further developed with quantitative modelling. Hazards which then endanger human life and assets which are valued by society are then termed risks (Elliott et al., 2014). For example, Baysian Belief Network modelling based on probabilities of cause and effect has recently been linked to Bow-tie analysis (Stelzenmüller et al, 2015). By linking this method to a $\operatorname{DAPSI}(\mathrm{W}) \mathrm{R}(\mathrm{M})$ approach with responses based on ten-tenets criteria, it enables the scoping, identification and analysis of:

i) the causes (based on the Drivers, Activities and Pressures) leading to the main events;

ii) anticipatory prevention measures (the Responses using Measures), including those limiting the severity of the main event;

iii) the consequences of the events (the State Changes and the Impacts on human Welfare), and

iv) mitigation and compensation measures (i.e. the Responses using Measures) aimed at minimising those consequences (Burdon et al., 2015).

Figure 1 shows a conceptual Bow-tie analysis model for inter alia three potential environmental issue causes related to ocean and short-sea transport and docking at port. As 
examples of a subset of environmental causes could be $\mathrm{CO}_{2}$ and $\mathrm{SO}_{2}$ emissions into the water (A), ballast water discharges into the water while in port (B), and emissions into the air eventually resulting in ocean acidification (C). Consequences of these causes could include inter alia high levels of biological pollutants (non-indigenous species) in the receiving environments (water and sediment); (E), harmful air emissions around the ship $(\mathrm{F})$, and an increase in human illness and disease as a result of increased emissions, discharges and acidification $(\mathrm{G})$.

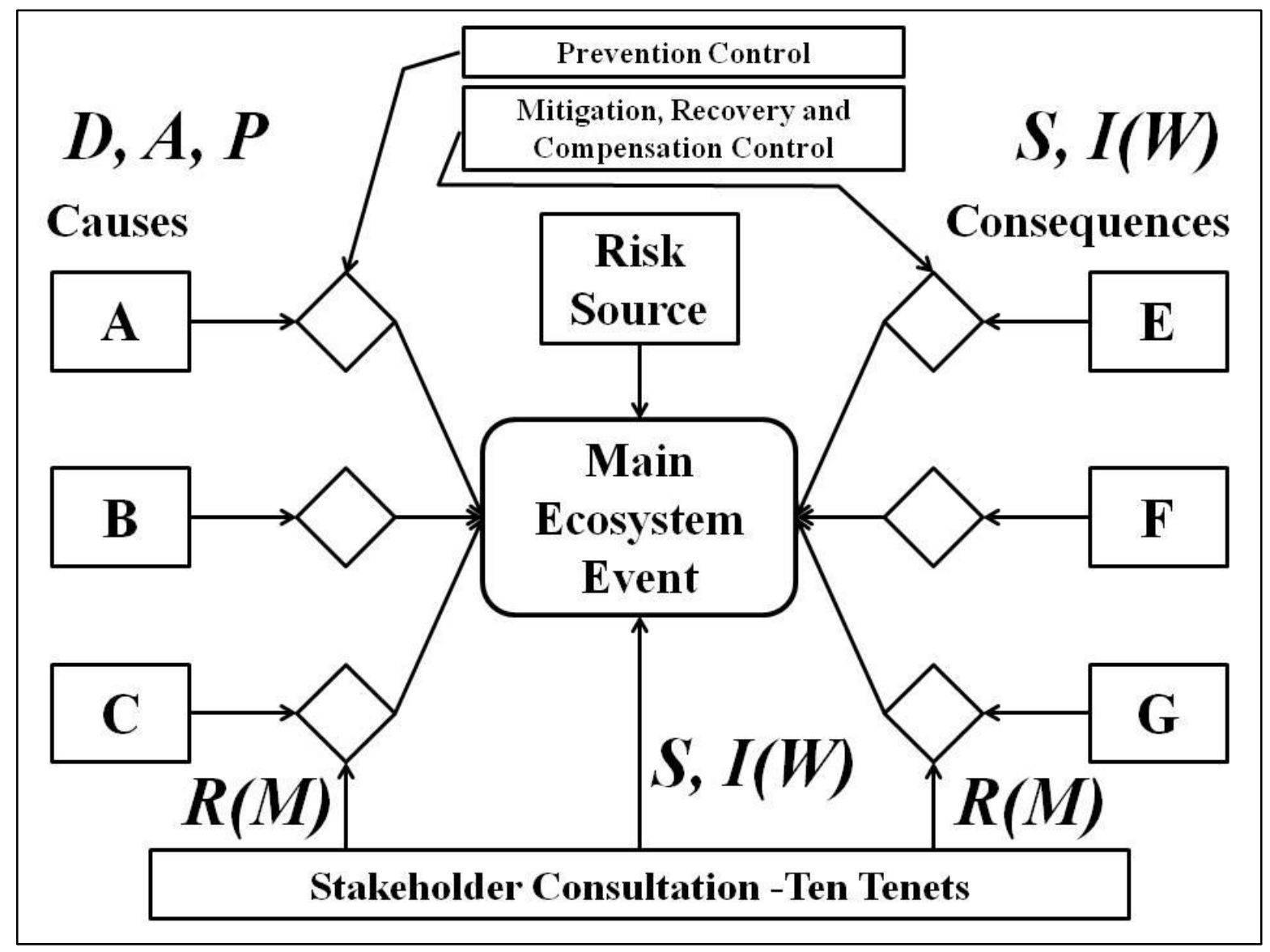

Figure 1 Conceptual Model using the DAPSI(W)R(M) structure and Bow-tie analysis for potential environmental issue causes

As noted above, our purpose is to integrate these three distinct techniques to assist researchers and organizations in making better sense of potential risks and mitigation strategies for environmental and/or sustainability issues. We focus on the marine sector for this paper around an example of in-port ballast water discharge and air emissions to 
illustrate the concepts and framework. However, we intend that this framework be available for wider use across many sectors, although it will require amending for different sectors and situations. Hence, while it is conceptual at this stage and generic by nature it is suitable for adoption by relevant organizations.

\subsection{Aerial emissions leading to ocean acidification and nutrient inputs}

Diffuse inputs resulting from the burning of fossil fuels, usually bunker oils, from oceangoing vessels, contain nitrous and sulphur oxides and carbon dioxide. While the former introduce nutrients into the air and then through precipitation into the sea and thus contributes to nutrient enrichment and possibly eutrophication (De Jonge and Elliott, 2001), the $\mathrm{CO}_{2}$ produces carbonic acid that increases the water acidity. Whereas the introduction of NIS may occur closer to port or at water exchange sites en route, aerial emissions occur throughout the whole journey.

\subsection{Aquatic emissions related to ballast water discharge}

Ballast water exchange, i.e. taking on or discharging ballast water, primarily occurs in ports for logistical reasons to maintain the ship level and attitude when loading or unloading. However, a vessel taking on ballast water in one global region, with its particular fauna and flora, and transporting it to and discharging it in another region thus leads to the transport of alien, invasive or non-indigenous species (NIS) which have the potential to disturb the ecological balance at the receiving area (Olenin et al., 2011, 2016; David and Gollasch, 2008). Ballast water discharge is regarded as an ancillary vector of NIS as organisms can also be transported on the hull, anchor and anchor chains.

The introduction of such alien species into port areas is currently a major environmental problem in several parts of the world (Perreria et al., 2016). However, freshwater or brackish-water organisms, taken from estuarine port areas, cannot survive full salinity seawater (at salinity 35 to 37 ). Hence, the major problem occurs in port regions and shippers and port operators need to be aware of this issue to ensure that the amount and types of NIS transport and re-location are minimal. 
Despite the above, proactive environmental actions by shipping companies are uncommon in the industry and little is known about their motivation regarding the implementation of green shipping practices or GSPs (Lai et al., 2011). However, GSPs are becoming more widely adopted as shipping companies come under stakeholder pressure from regulators, industrial norms and customers. Lai et al. (2011) postulated that shipping companies adopting GSPs to a greater extent will outperform their competitors that have not fully adopted GSPs. Thus, there is a symbiotic opportunity to satisfy improving the three criteria of planet, people and profit in the triple-bottom line (Elkington, 1994) through better BWM. The various ten-tenets criteria would need to be formalised to provide guidance regarding what Response Measures could be undertaken for prevention control as well as mitigation, recovery and compensation control. Our example formalisation for them is shown in Table 2 and we have provided subjective comments and an individual ranking for the ten criteria from 1 to 5, representing not important at all (score of 1), to very important (score of 5).

Identifying these elements in Table 2 provides a view of the State change on the natural system (S) in an ecosystem event that in turn generates Impacts (on human Welfare) (I(W)) and subsequent consequences. The importance of these then fits with the ultimate aim in marine management being to protect and maintain the natural functioning while delivering the ecosystem services and their resultant goods and benefits required by society (Elliott, 2011). We consider most of these criteria as important and necessary to avoid the consequences selected, as well as any others not contemplated in this example. The ratings in the second column of Table 2 reflect our subjective assessment of the criteria defined in Table 1. 
Table 2 The 10-Tenets applied to Ballast Water Discharge (Source: Authors)

\begin{tabular}{|l|l|l|}
\hline Tenet & Justification & Score \\
\hline Socially desirable/tolerable & Very important & 5 \\
\hline Ecologically sustainable & Very important and easy to do & 5 \\
\hline Economically viable & Neutral but should not cost too much & 3 \\
\hline Technologically feasible & Important and should be easy to do & 4 \\
\hline Legally permissible & $\begin{array}{l}\text { Important and should not be difficult to follow } \\
\text { legislatively }\end{array}$ & 4 \\
\hline Administratively achievable & $\begin{array}{l}\text { Important and should not be difficult to } \\
\text { administer }\end{array}$ & 4 \\
\hline Politically expedient & Important and a vote winner & 4 \\
\hline Ethically defensible & Important and should not be difficult to justify & 4 \\
\hline Culturally inclusive & Not an issue & 1 \\
\hline Effectively communicable & $\begin{array}{l}\text { Important and should not be difficult to } \\
\text { communicate }\end{array}$ & 4 \\
\hline
\end{tabular}

We next formulate our main ecosystem event process from a risk source related to water, i.e. a ship docked at a port development that is summarised in the conceptual model (horrendogram) shown in Figure 2 (see Smith et al., 2016 regarding conceptual models). The shaded boxes outline our specific examples of aerial and ballast water discharge for consideration, the first of which is especially relevant given that receiving ferry ports in the Baltic Sea region, e.g. Helsinki or Stockholm, show elevated levels of NIS (Olenin et al., 2011). Again, this manifests as an ecological change and the potential loss of ecosystem services and societal goods and benefits.

The Response (using Measures) for prevention control on the causation side of the Bow-tie could include monitoring of discharges through all of the ship discharge outlets via effluent sensors during each port of call along its route. The monitoring would need legislative support but while monitoring is not a preventative or control measure per se, it is required to determine whether any control mechanism is effective. This will allow the authorities to know whether or not a ship has discharged any contaminated ballast water, what the polluting components might be, and their percentage composition in the sample. Continuous monitoring would provide a baseline of what is 'normal' as well as what might 
be excessive. 


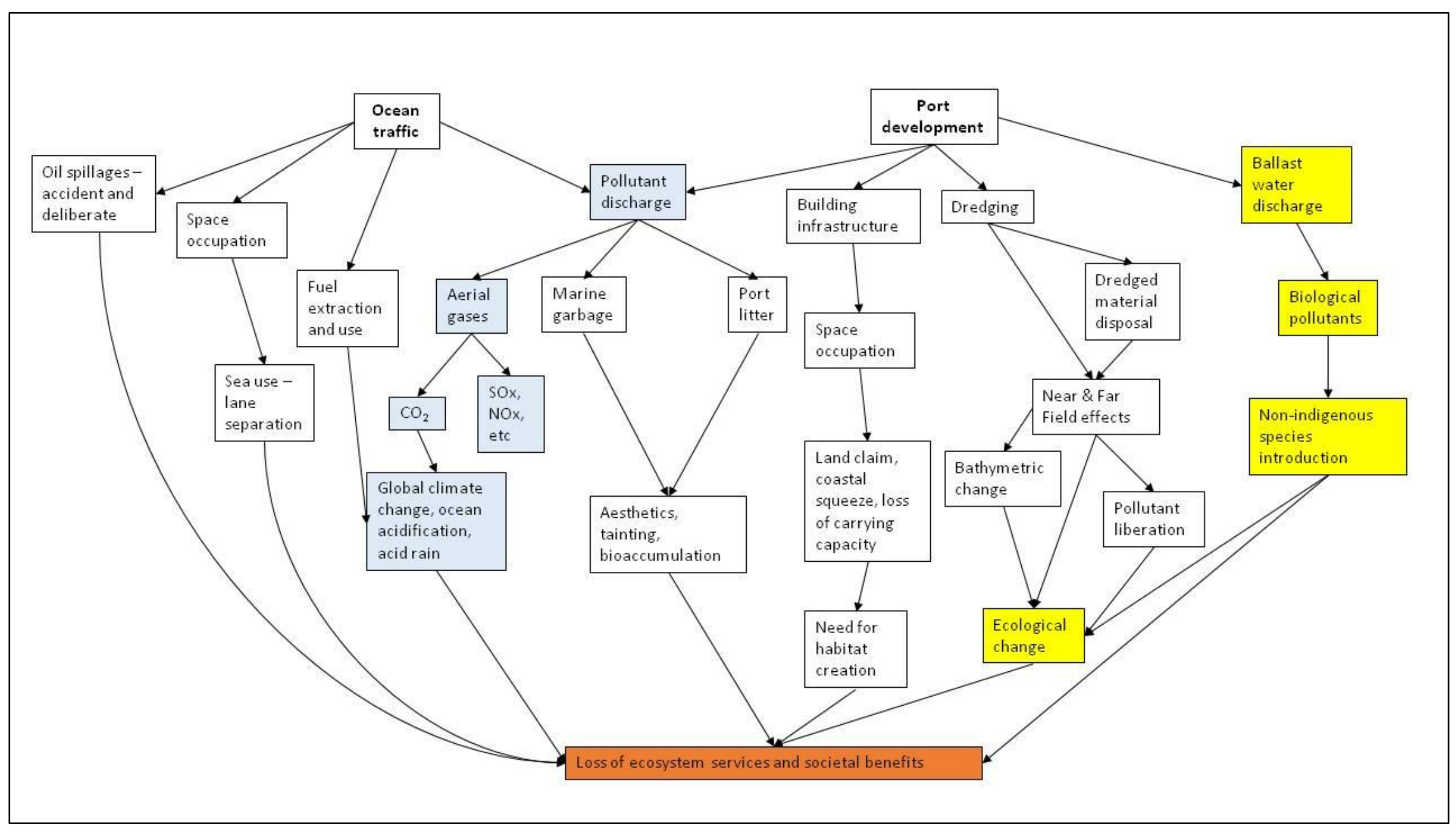

Figure 2 Horrendogram of ocean traffic and port development environmental effects highlighting ballast water discharge and aerial contaminants as the main ecosystem events 
If such a prevention control analysis determined that two ships were responsible for the excessive discharges, then specific mitigation, recovery and compensation controls could be applied as required. For example, mitigation could include preventing the two ships from sailing onward until their ballast water systems were repaired; this is a particular problem as it is axiomatic that with NIS entry from ballast water discharges it is not possible to eradicate the species in receiving open marine waters once liberated (Olenin et al., 2011, 2016). Indeed it is often the case that by the time an alien species is detected in the marine environment then it is already established and so the emphasis has to be on 'prevention rather than cure'.

As noted above, the International Convention for the Control and Management of Ships' Ballast Water and Sediment, which entered into force in September 2017, ensures that ballast water must be treated before it is released into any new location, either en route or in new ports. Further, any exchange en route is intended to be done 200 nautical miles from land or in water at least $200 \mathrm{~m}$ deep (unless there is a special exemption if these thresholds cannot be met). This will partially control the introduction of NIS, as long as there are no 'stepping stones' for organisms to hop across shipping routes (for example offshore structures such as oil and gas rigs and offshore wind turbine supports), and disinfection of ballast water through, for example, ozone treatment, would prevent NIS discharge either en route or at the receiving port.

We contend that the framework detailed here is merely a formalised and rigorous approach which summarises the risk assessment and risk management carried out daily by port and navigation managers. The strength of this framework comes from the interaction of many causes and many possible consequences for a particular ecosystem event. While limiting our overriding event of water pollution to one cause or event, ballast water discharges, it is necessary to consider the interactions among other potential causes or events occurring simultaneously, for example ballast water discharges, dredging, oil spillages and other polluting discharges.

Given these many activities and pressures, a major challenge in port and navigation management is to include the cumulative and in-combination effects of all activities within 
the shipping sector, between the shipping sector and other uses and users of the seas, and between those uses and users. Thus within this conceptual framework, the ten-tenets set the scene for what should be normative, acceptable management activities while the DAPSI(W)R(M) approach allows for a systemic and holistic consideration of the causes and consequences using the principles of bow-tie analysis accompanied by the relevant measures. As shown by Boyes and Elliott (2014, 2015), the control on marine activities and their repercussions requires an extensive legislative and administrative framework which ranges from the international (e.g. the International Maritime Organisation), through the regional (e.g. in Europe the EU Directives such as the Marine Strategy Framework Directive and the Maritime Spatial Planning Directive) to national legislation.

\section{Exploratory Study Research Design}

While this framework appears valuable and encompassing, the next step was to investigate its veracity and usability and to do so we used an exploratory and inductive study with maritime practitioners, i.e. shippers and port operators. In that regard the research design was essentially a multiple case study across multi-sites and with multi-informants to show similar or contrasting results (Ellram, 1996; Yin, 2013). Our objectives were to qualitatively solicit their views on, and investigate their interest in, using the framework to ascertain the validity of the framework. In the longer term, this approach will be progressed based on the findings from this small study and we aim to conduct an extended empirical study with a larger sample using quantitative methods survey to determine appropriate and acceptable measures for this framework and develop generalizable findings.

Accordingly, we used in-depth interviews that are an effective method in obtaining a rich understanding of a new, under-researched phenomenon such as our framework (Miles and Huberman, 1994). We developed questions from the literature and the framework's conceptual design for a semi-structured interview guide that is included in the Appendix. We developed three a priori questions or 'themes' for these interviews:

- What type of risks the organization considers important and the way in which they deal with them,

- What type of risk management systems and/or tools the organization currently uses, 
and

- Whether our framework would be useful to their organization, industry sector or in other sectors.

We also asked whether the organization would be interested in trialling it, some basic organization demographic data, and whether the organization had any other comments. However, we did not seek or review organizational documents.

Personal experience informed our sampling strategy as we invited potential interviewees based on our contacts with them. We aimed to interview up to ten companies, however this proved difficult to arrange and we were only able to interview five individuals in three companies. We assured interviewees of confidentiality regarding their identity and company.

Leonard and Sensiper (1998) consider that "explicit knowledge is shared through a combination process and becomes tacit through internalization; tacit knowledge is shared through a socialization process and becomes explicit through externalization". We consider all interviewees were informed due to their extensive experience and engagement with others in their sector and hence there was no requirement to determine their level of expert or tacit knowledge.

Interview transcripts were analysed using content and thematic analysis techniques to determine similarities and differences (Miles and Huberman, 1994). The purpose of thematic analysis is to identify sub-themes based on a prior themes or concepts, i.e. patterns in the data that are important or interesting, and use these sub-themes to address the research or say something about an issue. We read each interview in-depth but did not use qualitative data analysis software such as NVivo (Dey, 1993) as the small number of interviews did not justify its use.

The first step involved applying open coding to the transcript data to categorise the three a priori themes noted above: risk importance, risk management systems and/or tools used, and perceptions of the framework value, into codes reflecting similarities and differences. The next step involved using axial coding to interpret the open codes and make connections among the three themes (Ellram, 1996; Yin, 2013). 
The concept of trustworthiness and its four criteria determine qualitative research quality (Halldórsson and Aastrup, 2003) as opposed to usual quantitative quality measures of external and internal validity, reliability and objectivity (Guba and Lincoln, 1989). The four trustworthiness criteria are credibility (degree of match between respondent views of reality and the researcher representation of these views), transferability (extent to which the study is able to make general claims), dependability (concerned with the stability of data over time), and confirmability (findings represent the results of the inquiry and not the researcher's biases).

\section{Findings}

Table 3 provides generic information about the three company responses. As noted above we cannot name them or provide very specific demographic details for confidentially reasons. Following the table we recap the essence of each interview transcript across the three companies.

Table 3 Respondent Information

\begin{tabular}{|c|l|l|l|l|}
\hline Company & Type & Interviewees & Demographic Details \\
\hline A & $\begin{array}{l}\text { Shipper/ } \\
\text { Agent }\end{array}$ & $\bullet \quad$ Managing Director & $\begin{array}{l}\text { Multi-cargo UK shipper and } \\
\text { shipping agent specialising in } \\
\text { abnormal cargo solutions }\end{array}$ \\
\hline B & $\begin{array}{l}\text { Port } \\
\text { Operator }\end{array}$ & $\begin{array}{l}\text { - } \\
\bullet\end{array}$ & $\begin{array}{l}\text { Health \& Safety Manager; } \\
\text { Conservancy Operations } \\
\text { Manager }\end{array}$ & $\begin{array}{l}\text { Multi-site UK port operator } \\
\text { handling general cargo and } \\
\text { container ships }\end{array}$ \\
\hline C & Shipper & $\bullet \quad$ Managing Director & $\begin{array}{l}\text { UK subsidiary of northern } \\
\text { Europe shipping operator } \\
\text { handling roll-on, roll-off (Ro- } \\
\text { Ro) and passenger ship } \\
\text { services }\end{array}$ \\
\hline
\end{tabular}

\subsection{Company A}

The Managing Director for Company A, a shipper and shipping agent, identified the 
important marine risks as a shipping agent to safeguard a ship owner's interests regarding issues of fuel oil spillage or 'slops' in tanks or ballast tanks, ballast water, low sulphur fuel, and garbage. As an own-shipper, the company is concerned with issues of fuel, $\mathrm{CO}_{2}$ emissions, ballast water with its own system or port-side cleaning, and spill prevention control and countermeasure (SPCC) systems for good port behaviour. Company A assesses risk as a shipping agent by checking with the ship's captain to ensure garbage removal, fuel oil slops and cleaning of ballast water and dunnage, particularly wood, are completed. All of its ships have an electronic and manual file or log to assess and manage any risks. Company A uses ISO 9001 as a quality and risk management tool for its ships on the water, as well as for the small road haulage element of their business. Regarding the proposed framework, Company A, the Managing Director first noted that a problem regarding how a business is run sustainably relates to the penalty for not complying either with guidelines or legislation. He suggested that many companies in his sector and elsewhere are not truthfully looking to work with the environment; they are following the letter but not always the spirit of the legislation ('talking the talk but not walking the walk'). The Managing Director considers the framework is relatively valuable but should be reduced to a simple check-list to consider and deal with risk, and focus on particular and specific issues. There is also an issue of the split between ports and shipping regarding who is fully responsible for managing the environmental risks. Company A would not be suitable to trial the framework given their intermediary role as agent.

\subsection{Company $B$}

Company B is a port operator and its three individuals responsible for sustainability and risk management participated in the research. They identified important risks relevant to their operations as buildings and infrastructure, dredging of the port area and disposal of dredged material, discharge of pollutants, proper space occupation by users in port i.e. ships, oil spillages (accidental and deliberate), handling of ballast water and aerial gases (emissions). Company B assesses these risks by environmental impact assessment and planning regulations for building infrastructure, Port Marine Safety Code (PMSC) risk assessment for Oil spills and space separation of vessels, baseline protocols for dredging, 
environmental impact assessment for pollutant discharge from the port, and monitoring. They also liaise with local statutory bodies such as the national (in this case English) environment, maritime safety, nature conservation and fisheries agencies. They have responsibilities for ballast water discharge, contingency planning, harbour authority duties and vessel traffic service (VTS) traffic management systems for managed space separation. They manage such risks by using an oil spill response plan, response equipment and drills and bunkering procedures for vessels, baseline protocols, monitoring of change and risk. They interact and comply with the main English marine statutory body, the Marine Management Organisation (MMO) for disposal consents and consents for dredging, environmental management system and procedures for pollution, environmental impact assessment for building infrastructure, and relying on compliance with international regulations ballast water. This breadth of agencies, bodies and duties emphasises the complex nature of marine and estuarine management in a developed European maritime state such as the UK (Lonsdale et al, 2015, 2018; Boyes and Elliott, 2015). The types of risk management systems and/or tools currently used by Company B include using baseline protocols for dredging, the PMSC and adaption of the BOMEL plc assessment protocol using an online-based system designed for ports, ISO 14001 for environmental impact assessment, and planning application requirements. They suggested the proposed framework was too broad and should be developed to include sufficient detail for practical implementation and as such at present is open to very wide interpretation. Further, they needed certainty about for whom it is meant to apply. The three respondents believe the 10tenets criteria are good but that their individual assessments should be judged against each other and they need to be developed into more of a working tool. Thus they believe that the framework is currently not yet suitable for a practical application and needs more detail and further development for more practical use. Despite this, Company B agreed that they would trial the framework and indicated they will try and apply it on current expansion and development plans.

\subsection{Company $C$}

Company $\mathrm{C}$ is a shipper and the Managing Director identified important risks as oil leakage 
during bunkering or due to grounding, chemical leakage from cargo units, fire on board, sewage from Ro-Ro vessels to sea, and open loop sulphur scrubber system effluent to sea. Risk assessment is done in connection with annual business planning and tools used include risk importance/likelihood where possible preventive actions are also identified. Their environmental risk management integrates tightly with a Maritime Safety and Quality Management system. Information from near-miss and actual incidents are collected from vessels into a common incident handling system and corrective actions are done based on reports. The Managing Director considered that this kind of systematic and profound analysis would enable more efficient focusing of preventive and corrective actions and would also be good to review different stakeholder aspects related to the risks. However, he considered that it is too labour intensive at present to be implemented with short notice in practice. So, while the framework would be good to have it would need some simplifying as well as a supporting tool. Company $\mathrm{C}$ would not be able to trial the framework in its present form.

\subsection{Discussion}

Table 4 shows the summary results of the open and axial coding techniques used. The small number of interviewees was disappointing however we received relatively good and consistent information from our interviewees. Of course, this is not data saturation in a qualitative research context (Guba and Lincoln, 1989) but responses regarding our three themes showed good similarities as well as some differences. We thus believe we reached a level of consensus that provides confidence and leads us to believe our trustworthiness elements and criteria has enabled collection of rich data anticipated.

The findings suggest all three respondent firms consider important sustainability risks with various discharges and prevention of them being similar. Further, all of them use various risk management techniques and systems applicable to their sector and operations. However, such sectoral operations represent a differential factor among them. Companies $\mathrm{A}$ and $\mathrm{C}$, who are shippers, are concerned with risks 'on the water' while their ships are at sea. However, Company B as a port operator is concerned with risks to their landside operations, including buildings and infrastructure, as well as dredging to ensure ships can 
dock. Their respective views are as expected given their supply chain positions and roles but possibly demonstrate a lack of a holistic sustainability perspective. This was highlighted by Company A, who wondered about where responsibilities lie among firms, and Companies B and C who respectively consider the framework is too broad. This possibly encompasses issues not in their purview, and needs simplification as it appears to labour intensive i.e. possibly beyond their scope. In addition, we emphasise that it shows such companies do require training and CPD (continued professional development) for staff in these environmental management aspects.

Thus, our framework as presented here has value according to the respondent companies, but requires additional work to simplify it for further use. Despite that, further developments and refinements for other applications reported elsewhere (Lonsdale et al., 2015, 2018) have shown the potential for building the approach into a data-rich GIS-based system to satisfy the regulators. Its use would involve perhaps not exposing the users to all elements at once but leading them through the framework with training. The findings here suggest that such a system can be developed for the logistics industry. This would require development of the conceptual perspective to clarify its progression and linkages based on the findings. 
Table 4 Summary of Thematic Analysis

\begin{tabular}{|c|c|c|c|c|}
\hline \multirow[t]{2}{*}{$\begin{array}{c}\text { Case } \\
\text { Company }\end{array}$} & \multicolumn{3}{|c|}{$\begin{array}{c}\text { Open Coding Categorization of } A \text { Priori Themes from } \\
\text { Interview Transcripts }\end{array}$} & \multirow[t]{2}{*}{$\begin{array}{c}\text { Framework } \\
\text { Trial? }\end{array}$} \\
\hline & Important Risks & $\begin{array}{c}\text { Risk } \\
\text { Management }\end{array}$ & $\begin{array}{l}\text { Framework } \\
\text { Usefulness }\end{array}$ & \\
\hline $\begin{array}{l}\text { A - Shipper } \\
\text { / Agent }\end{array}$ & $\begin{array}{l}\text { Fuel; } \mathrm{CO}_{2} ; \\
\text { Ballast water } \\
\text { discharges; Spill } \\
\text { prevention and } \\
\text { control }\end{array}$ & $\begin{array}{l}\text { ISO 9001; } \\
\text { concerns about } \\
\text { those who } \\
\text { comply only to } \\
\text { minimise } \\
\text { penalties }\end{array}$ & $\begin{array}{l}\text { Valuable, but reduce } \\
\text { to simple checklist } \\
\text { focussed on specific } \\
\text { risks; Split of } \\
\text { responsibilities }\end{array}$ & No \\
\hline $\begin{array}{l}\text { B - Port } \\
\text { Operator }\end{array}$ & $\begin{array}{l}\text { Building and } \\
\text { infrastructure; } \\
\text { Dredging; } \\
\text { Pollutant } \\
\text { disposal; Ballast } \\
\text { water discharge }\end{array}$ & $\begin{array}{l}\text { PMSC; MMO; } \\
\text { BOMEL } \\
\text { protocol; ISO } \\
14001\end{array}$ & $\begin{array}{l}\text { Good, but too broad } \\
\text { and should provide } \\
\text { sufficient detail for } \\
\text { who it should apply } \\
\text { to; Not yet suitable } \\
\text { for practical } \\
\text { application }\end{array}$ & Yes \\
\hline C - Shipper & $\begin{array}{l}\text { Bunker oil } \\
\text { leakage; Cargo } \\
\text { chemical } \\
\text { leaking; Fire; } \\
\text { Sewage from Ro- } \\
\text { Ro; SO2 } \\
\text { scrubber } \\
\text { discharge }\end{array}$ & MSMQ system & $\begin{array}{l}\text { Systematic and } \\
\text { profound, but too } \\
\text { labour intensive and } \\
\text { simplification needed }\end{array}$ & $\begin{array}{l}\text { Not in } \\
\text { present } \\
\text { form }\end{array}$ \\
\hline $\begin{array}{l}\text { Axial } \\
\text { Coding } \\
\text { Connections } \\
\text { across } \\
\text { Themes }\end{array}$ & $\begin{array}{l}\text { Discharges and } \\
\text { prevention; } \\
\text { distinctive } \\
\text { operational } \\
\text { setting }\end{array}$ & $\begin{array}{l}\text { Sector specific } \\
\text { systems or } \\
\text { tools; not all } \\
\text { related to } \\
\text { sustainability }\end{array}$ & $\begin{array}{l}\text { Supported } \\
\text { framework and its } \\
\text { purpose, but more } \\
\text { simplicity as well as } \\
\text { detail required }\end{array}$ & \\
\hline
\end{tabular}

\section{Concluding Remarks}

This paper has developed, tested and proposed an integrative conceptual framework for balancing hard, quantitative environmental sciences and soft, qualitative management sciences within the logistics arena. Our example about ballast-water and air-borne emissions discharges illustrates the way that the framework could be used in practice by researchers, businesses, governments and other stakeholders. In doing so it allows us to combine work in logistics, supply chain management and the marine and estuarine sciences and management. 
In particular, this novel framework is the culmination of several concurrent but different strands of research primarily in marine sciences and shows the cross-over between the natural and social sciences and environmental management. Thus, there is a need to empirically test the framework in an in-depth research study to verify it veracity and robustness. Its success depends on the adequacy of our conceptual knowledge of the causes and consequences of human activities, our understanding of the structure and functioning of the marine system and our ability to quantify those interactions. It requires port and navigation managers to embrace and understand the plethora of decisions affecting the environmental, economic, technical, societal and legal frameworks and hence will need greater training and continuing professional development (CPD) in these aspects. It also requires environmental managers and regulators further to understand the constraints of global port and shipping operations.

Following this, the exploratory research study into the veracity and usability of the framework presented here has allowed the framework to be taken from an academic to an applied industrial context. The five respondents raised several important aspects. As all companies recognised potential risk areas that are applicable to their respective companies suggests that the development of a horrendogram-based conceptual model of risk factors is appropriate for the maritime sector. However, all companies considered that the framework as presented is either too complex or insufficiently simple for companies and other organizations to understand in order to be able to be implemented. Presenting all possible repercussions and linkages in the form of conceptual models (horrendograms) has both advantages and disadvantages (see Burdon et al., 2018 for a further use of the Bow-tie methodology). The diagrams are valuable in conveying a message that many aspects are linked, that natural and social systems are complicated, and organisations require multi- and cross-disciplinary approaches and ways of thinking.

We emphasise here that while it is valuable to show the complexity and the means of linking all aspects, it is possible that such complexity overwhelms organisations. We emphasise that in certain circumstances it is important to show the complexity, thus explaining why solutions require multidisciplinary approaches, whereas in other circumstances for industries it would be more appropriate to show only elements of the horrendogram and thus talk the industry through the complexity. Hence, companies need 
advice and assistance in working with and within the regulatory system and in following the plethora of marine legislation. However, it is encouraging that recent interdisciplinary attempts to bring together the plethora of organisations, frameworks and regulatory instruments (Lonsdale et al., 2018) show that we have built on several decades of development.

Similarly, companies and environmental managers may also face 'consultation fatigue', given the number of interactions, and may not have the requisite number of skills and amount of expertise, and be concerned at the financial and time costs of following complex environmental management systems. Hence, given the complexity of the frameworks, we suggest that as a communication and analysis tool it may be better to present and explain small elements of the framework (à la Elliott, 2014) rather than the whole system at one time.

The complexity of the horrendogram due to its large scope may not have let the organisations properly delineate their areas of responsibility for risk assessment and management. This in turn affected their ability to assess the framework on the totality of the three elements underlying it - the 10-tenets criteria, the DAPSI(W)R(M) problem setting approach and the Bow-tie analysis. Indeed, the question from Company A regarding dividing the responsibility between ports and shippers, and the port operator's confusion about for whom the framework is intended underscores that issue. However, all companies also believed there is merit in the holistic framework, particularly the 10-tenets criteria and even though Company B required more explanation of how it would work in practice. It is of note that two respondents are interested in trialling the framework to see if it can improve their risk assessment and measurement.

Finally, future work should include aspects regarding the importance of training and CPD of companies and their staff in environmental awareness and control. Company B's concurrence that they would trial the framework to possibly apply to its current expansion and development plans highlights a need companies to consider human resource development in the growing landscape of sustainability within companies and organizations.

In summary, we are encouraged by the responses from these three companies as all 
indicated the framework has potential and none rejected it out of hand. We appreciate that five interviews is a small sample, however this work was exploratory and a consensus achieved nonetheless. Hence, the findings give us a good platform to proceed with further framework development and testing in a bid to allow companies to substantially analyse their environmental management efforts. With greater information and further data it will be possible to convert the framework described here to a decision support system aiming for real-time management of the activities and their consequences.

\section{Acknowledgements}

We thank the referees and Editor-in-Chief for their valuable comments and discussions on earlier versions of the paper.

\section{References}

Aravossis, K., Pavlopoulou, Y., 2013. Creating shared value with eco-efficient and green chemical systems in ship operations and in ballast water management. Fresen Environ Bull. 22 (12a), 1-9.

Atkins, J.P., Burdon, D., Elliott, M., Gregory, A.J., 2011. Management of the marine environment: Integrating ecosystem services and societal benefits with the DPSIR framework in a systems approach. Mar Pollut Bull. 62, 215-226.

Barnard, S., Elliott, M., 2015. The 10-tenets of adaptive management and sustainability applying an holistic framework for understanding and managing the socioecological system. Environ Sci Policy. 51, 181-191.

Borja, Á., Dauer, D.M., 2008. Assessing the environmental quality status in estuarine and coastal systems: comparing methodologies and indices. Ecol Indic. 8 (3), 331-337.

Borja, Á., Elliott, M., Uyarra, M. C., Carstensen, J., Mea, M., (Eds.) 2016. (2017). Bridging the Gap Between Policy and Science in Assessing the Health Status of Marine Ecosystems, 2nd Edition. Lausanne: Frontiers Media. doi: 10.3389/978-2-88945126-5; pp548; downloaded from http://www.frontiersin.org/books/Bridging_the_Gap_Between_Policy_and_Science in_Assessing the_Health_Status_of_Marine_Ecosystems_2nd/1151, (accessed 12 December 2017).

Boyes, S.J., Elliott, M., 2014. Marine legislation - The ultimate 'horrendogram': International law, European directives \& national implementation. Mar Pollut Bull. 86, 39-47.

Boyes, S.J. Elliott, M., 2015. The excessive complexity of national marine governance systems - has this decreased in England since the introduction of the Marine and Coastal Access Act 2009? Mar Policy. 51, 57-65. 
Boyes, S.J., Elliott, M., Thomson, S.M., Atkins, S., Gilliland, P., 2007. A proposed multiple-use zoning scheme for the Irish Sea: An interpretation of current legislation through the use of GIS-based zoning approaches and effectiveness for the protection of nature conservation interests. Mar Policy. 31, 287-298.

Burdon, D., Boyes, S.J., Elliott, M., Smyth, K., Atkins, J.P., Barnes, R.A., Wurzel, R.K., (2018). Integrating natural and social marine science to sustainably manage vectors of change: Dogger Bank transnational case study. Estuar Coast Shelf S.201, 234247.

Corbett, J.J., Winebrake, J.J., Green, E.H., Kasibhatla, P., Eyring, V., Laurer, A., 2007. Mortality from Ship Emissions: A Global Assessment. Environ Sc Technol. 41 (24), 8512-8518.

Cormier, R., Kannen, A., Elliott, M., Hall, P. Davies, I.M. (Eds) 2013. Marine and Coastal Ecosystem-based Risk Management Handbook. ICES Cooperative Research Report No. 317 March 2013. International Council for the Exploration of the Sea, Copenhagen.

David, M., Gollasch, S., 2008. EU shipping in the dawn of managing the ballast water issue. Mar Pollut Bull. 56, 1966-1972.

De Jonge, V.N., Elliott, M., 2001. Eutrophication. in: J Steele, S Thorpe, K Turekian (Eds.) Encyclopedia of Ocean Sciences. Volume 2, Academic Press, London, 852-870.

De Jonge, V.N., Elliott, M. 2002. Causes, historical development, effects and future challenges of a common environmental problem: eutrophication. Hydrobiologia 475/476, 1-19.

Dey, I., 1993. Qualitative Data Analysis: A User Friendly Guide for Social Scientists. Routledge, London.

EcoPorts, 2017. Ecoports. https://www.ecoports.com/, (accessed 29 November 2017).

Elkington, J., 1994. Towards the sustainable corporation: win-win-win business strategies for sustainable development. Calif Manage Rev. 36 (2), 90-100.

Elliott, M., 2003. Biological pollutants and biological pollution - an increasing cause for concern. Mar Pollut Bull. 46, 275-280.

Elliott, M., 2013. The 10-tenets for integrated, successful and sustainable marine management. Mar Pollut Bull. 74, 651-655.

Elliott, M., 2014. Integrated marine science and management: wading through the morass. Mar Pollut Bull. 86, 1-4.

Elliott, M., Borja, Á., McQuatters-Gollop, A., Mazik, K., Birchenough, S., Andersen, J.H., Painting, S., Peck, M., 2015. Force majeure: will climate change affect our ability to attain Good Environmental Status for marine biodiversity? Mar Pollut Bull. 95, 727.

Elliott, M., Burdon, D., Atkins, J.P., Borja, Á., Cormier, R., de Jonge, V.N., and Turner, R.K., 2017. And DPSIR begat DAPSI(W)R(M)! - A unifying framework for marine environmental management. Mar Pollut Bull. 118, 27-40. 
Elliott, M., Cutts, N.D., Trono, A. 2014. A typology of marine and estuarine hazards and risks as vectors of change: a review for vulnerable coasts and their management. Ocean Coast Manage. 93, 88-99.

Ellram, L.M. 1996. The use of the case study method in logistics research. Journal of Business Logistics. 17 (2), 93-138.

Enquist, C.A.F., Jackson, S.T., Garfin, G.M., and 27 others, 2017. Foundations of translational ecology. Front Ecol Environ. 15, 10, 541-550.

ECSA, 2017. European Community Shipowners' Association.http://www.ecsa.eu/, (accessed 29 November 2017).

F-CCA, 2016. Florida-Caribbean Cruise Association Industry Overview 2015. http://www.f-cca.com/downloads/2015-Cruise-Industry-Overview-andStatistics.pdf (accessed 4 February 2016).

Ferdous, R., Khan, F., Sadiq, R., Amyotte, P., Veitch, B., 2009. Handling and updating uncertainties in event tree analysis. Process Safety and Environmental Protection. 87, 283-292.

Ferdous, R., Khan, F., Sadiq, R., Amyotte, P., Veitch, B., 2012. Handling and updating uncertain information in bow-tie analysis. J Loss Prevent Proc. 25, 8-19.

Gibbs, D., Rigot-Muller, P., Mangan, J., Lalwani, C., 2014. The role of sea ports in end-toend maritime transport chain emissions. Energ Policy. 64, 337-348.

Grant, D.B., 2012. Logistics Management. Pearson Education, London.

Grant, D.B., Trautrims, A., Wong, C.Y., 2015. Sustainable Logistics and Supply Chain Management, revised ed. Kogan Page, London.

Gray, J.S., Elliott, M. 2009. Ecology of Marine Sediments: Science to Management. Oxford University Press, Oxford.

Guba, E., Lincoln, Y.S., 1989. Fourth Generation Evaluation. Sage, Newbury Park.

Halldórsson, Á., Aastrup, J., 2003. Quality criteria for qualitative inquiries in logistics. Eur J Oper. 14, 321-332.

Halpern, B.S., Walbridge, S., Selkoe, K.A., Kappel, C.V., Micheli, F., D'Agrosa, C., Bruno, J.F., Casey, K.S., Ebert, C., Fox, H.E., Fujita, R., Heinemann, D., Lenihan, H.S., Madin, E.M.P., Perry, M.T., Selig, E.R., Spalding, M., Steneck, R., Watson, R., 2008. A Global Map of Human Impact on Marine Ecosystems. Science. 319, 948952.

Hassellöv, I-M., Turner, D.R., Lauer, A., Corbett, J.J., 2013. Shipping contributes to ocean acidification. Geophys Res Lett. 40, 2731-2736.

Holthof, P., 2014. Size, scope and diversity of the world ferry fleet. http://www.interferry.com/wp-content/uploads/2A_Presentation_Holthof.pdf (accessed 4 February 2016).

Kun, Q., Gui-jun, D., Zhang, P-F. 2015. Research on Risk Management Strategy of Shipping Enterprise. Journal of Shipping and Ocean Engineering. 5, 75-79. 
Kuznetsov, A., Dinwoodie, J., Gibbs, D., Sansom,M. Knowles, H. 2015. Towards a sustainability management for smaller ports. Mar. Policy. 54. 59-68.

Lai, K-H., Lun, V.Y.H., Wong, C.W.Y., Cheng, T.C.E. 2011. Green shipping practices in the shipping industry: Conceptualization, adoption, and implications. Resour Conserv Recy. 55, 631-638.

Lam, J.A.L., Lai, K-H., 2015. Developing environmental sustainability by ANP-QFD approach: the case of shipping operations. J Clean Prod. 105, 275-284.

Lehmann, A., Hinrichsen, H-H., Getzlaff, K., 2014. Identifying potential high risk areas for environmental pollution in the Baltic Sea. Boreal Environ Res. 19, 140-152.

Leonard, D., Sensiper, S. 1998. The role of tacit knowledge in group innovation. California Management Review. 40, 112-132.

Lonsdale, J, Nicholson, R, Weston, K, Elliott, M, Birchenough, A, Sühring, R., 2018. A user's guide to coping with estuarine management bureaucracy: An Estuarine Planning Support System (EPSS) tool. Mar Pollut Bull. 127, 463-477.

Lonsdale, J., Weston, K., Barnard, S., Boyes, S.J., Elliott, M. 2015. Integrating Management Tools and Concepts to Develop an Estuarine Planning Support System: A case study of the Humber Estuary, Eastern England. Mar Pollut Bull. 100, 393-405.

Lonsdale, J. Weston, K. Blake, S. Edwards, R. Elliott, M. 2017. The Amended European Environmental Impact Assessment Directive: UK marine experience and recommendations. Ocean Coast Manage. 148, 131-142.

McKinnon, A., 2014. The possible influence of the shipper on carbon emissions from deepsea container supply chains: An empirical analysis. Maritime Economics \& Logistics. 16, 1-19.

McLusky, D.S., Elliott, M., 2004. The Estuarine Ecosystem: Ecology, threats and management, third ed. Oxford University Press, Oxford.

Miles, N., Huberman, A., 1994. Qualitative data analysis: A source book of new methods $\left(2^{\text {nd }}\right.$ edition $)$. Sage, London.

Newton, A., Elliott, M. A typology of stakeholders and guidelines for engagement in transdisciplinary, participatory processes. Front Mar Sci. 3, 230.

Olenin, S., Elliott, M., Bysveen, I., Culverhouse, P., Daunys, D., Dubelaar, G.B.J., Gollasch, S., Goulletquer, P., Jelmert, A., Kantor, Y., Mézeth, K.B., Minchin, D., Occhipinti-Ambrogi, A., Olenina, I., Vandekerkhove, J., 2011. Recommendations on methods for the detection and control of biological pollution in marine coastal waters. Mar Pollut Bull. 62, 2598-2604.

Olenin, S., Narŝcius, A., Gollasch, S., Lehtiniemi, M., Marchini, A., Minchin, D., Srèbalienè, G., 2016. New Arrivals: An Indicator for Non-indigenous Species Introductions at Different Geographical Scales. Front. Mar. Sci. 3, 208.

OSPAR Commission, 2009. Assessment of the impacts of shipping on the marine environment. OSPAR Commission, London. 
Patrício, J., Elliott, M., Mazik, K., Papadopoulou, K.-N., Smith, C.J. 2016. DPSIR-Two decades of trying to develop a unifying framework for marine environmental management? Front Mar Sci. 3, 177.

Pereira, N.N., Colombo, F.B., Chávez, M.I.A., Brinati, H.L., Carreño, M.N.P., 2016. Challenges to implementing a ballast water remote monitoring system. Ocean Coast Manage. 131, 25-38.

Pörtner H.O., Karl, D., 2014. Chapter 6 Ocean Systems. IPCC WGII AR5 Chapter 6, 138.

Rigot-Muller, P., Lalwani, C., Mangan, J., Gregory, O., and Gibbs, D., 2013. Optimising end-to-end maritime supply chains: a carbon footprint perspective. The International Journal of Logistics Management. 24, 407-425.

Vesely, W.E., Goldberg, F.F., Haasl, D.F., Roberts, N.H., 1981. Fault Tree Handbook NUREG-0492. US Nuclear Regulatory Commission, Washington DC.

Scharin, H., Ericsdotter, S., Elliott, M., Turner, R.K., Niiranen, S., Rockström, J., Blenckner, T., Hyytiäinen, K., Ahlvik, L., Ahtiainen, H., Artell, J., Hasselström, L., Söderqvist, T., 2016. Processes for a sustainable stewardship of marine environments. Conf EEA C. 128, 55-67.

Smith, C.J., Papadopoulou, K-N., Barnard, S., Mazik, K., Elliott, M., Patrício, J., Solaun, O., Little, S., Bhatia, N., Borja, A., 2016. Managing the Marine Environment, Conceptual Models and Assessment: Considerations for the European Marine Strategy Framework Directive. Front Mar Sci. 3, 144.

Stelzenmüller, V., Fock, H.O., Gimpel, A., Rambo, H., Diekmann, R., Probst, W.N., Callies, U., Bockelmann, F., Neumann, H., Kröncke, I., 2015. Quantitative environmental risk assessments in the context of marine spatial management: current approaches and some perspectives. ICES J Mar Sci. 72, 1022-1042.

Tournadre, J., 2014. Anthropogenic pressure on the open ocean: The growth of ship traffic revealed by altimeter data analysis. Geophys Res Lett. 41, 7924-7932.

Winebrake, J.J., Corbett, J.J., Green, E.H.M., Lauer, A., Eyring, V., 2009. Mitigating the health Impacts of Pollution from Oceangoing Shipping: An Assessment of LowSulfur Fuel Mandates. Environ Sci Technol, 43 (13), 4776-4782.

Wolanski, E., Elliott, M., 2015. Estuarine Ecohydrology: An introduction. Elsevier, Amsterdam.

Yin, R. K. 2013. Case Study Research: Design and Methods ( $4^{\text {th }}$ edition). Sage, Thousand Oaks, CA. 


\section{Appendix: Semi-Structured Interview Guide}

1. Please identify which risks you think your firm poses for the natural environment relative to its operations. Which are the most important and why?

2. How does your firm currently assess these risks?

3. How does your firm currently manage these risks?

4. Does your firm currently use any risk management frameworks and if so which ones? Why did your firm select these frameworks?

5. What are your initial impressions/ views of our recently developed environmental risk assessment and management framework? Do you have any questions about it?

6. Do you believe that the three underlying elements [10-tenets criteria, DAPSI $(W) R(M)$ method, and Bow-tie analysis] are sufficient and complete to assess and manage risk in? Why? If no, why not?

7. Do you believe this framework will work in an operational and business setting in general and in your firm in particular? Why? If no, why not?

8. Would you and/ or your firm be interested in trialing this framework with some specific risks you consider important to assess its efficacy, usability and applicability?

9. Could you please tell me a little bit about your firm regarding its demographics, operations and geographic areas of business?

10. Any final comments? 